\title{
Explanations of prospective middle school mathematics teachers for potential misconceptions on the concept of symmetry *
}

\begin{tabular}{ll}
\hline Received: & 26 May 2017 \\
Revised: & 09 August 2017 \\
Accepted: & 01 Sept. 2017 \\
ISSN: 1307-9298 \\
Copyright $\odot$ IEJEE \\
www.iejee.com
\end{tabular}

DOI: 10.26822/iejee.2017131888

\author{
Mihriban Hacisalihoğlu Karadeniz a, Tuğba Baran Kaya ${ }^{b}$ \\ Figen Bozkuş ${ }^{c}$
}

\begin{abstract}
This study is an explanatory study, which follows a qualitative methodology and aims to reveal the explanations of prospective mathematics teachers for the potential misconceptions of secondary school students in relation to the concept of symmetry and the correction of such misconceptions. The study group consisted of a total of 26 prospective middle school mathematics teachers, who were senior students. The data of the study were obtained from the open-ended test prepared by the researchers. Following the data analysis, it was found out that the majority of the participants failed to identify the mistakes of students and suggested the ways to "letter the corners of the shape and measure the distance based on the axis of symmetry" in order to correct these mistakes. Moreover, the study notably observed that the participants adopted practical solutions such as the use of a mirror, paper folding, and the use of unit squares more in teaching the concept of symmetry. It may be stated that the prospective teachers, in this way, overlooked the development of conceptual knowledge in students.
\end{abstract}

Keywords: Concept of symmetry, conceptual mistakes, prospective middle school mathematics teachers

\section{Introduction}

The importance of conceptual knowledge in mathematics has been acknowledged. For an effective teaching of mathematics, students should acquire the relevant concepts of the subject. Conceptual knowledge is a type of knowledge based on comprehension including the skills such as symbolizing mathematical concepts, presenting them in a different form, establishing relationships between them and performing mathematical operations in relation to them (Birgün \& Gürbüz, 2009).

Therefore, meaning is important in conceptual knowledge. As long as the meaning of the concept is understood, conceptual knowledge is developed (Baki \& Kartal, 2004). A single concept does not mean anything on its own in mathematics. If the concept to be learned is associated with other mathematical concepts, such concept makes sense and conceptual learning is achieved in the mind of an individual (Baki, 2006). In case that the concepts could not be accurately developed in one's mind, they may have misconceptions or difficulties with the concepts.

Misconception is defined as the ideas that do not agree with the current scientific view, arising from prior learning of students, as a student conception producing a systematic pattern of errors (Smith, Disessa \& Roschelle 1993). Oliver (1989) reports that a misconception results from the beliefs and principles in the cognitive structure underlying systematic conceptual errors. Students, in line with their beliefs and prior learning, consider the concepts that they have misconceptualized as accurate and depend on them in demonstrating many skills. Swan (2001) states that a misconception stems from a developing concept or the generalization of the concept by students, rather than their wrong thinking. Further, Swan (2001) argues that misconception may be a natural stage in conceptual development. Therefore, the misconceptions that students have should not be considered as their failure. Moreover, Zembat (2010) reports that misconceptions may be also triggered by teaching methods. In this regard, the conceptual knowledge of teachers and the teaching environment that they create are of importance. Teachers should be aware of the existing or potential misconceptions that students have. In this way, they should change the misconceptions of students and determine the teaching strategies and approaches that transform these misconceptions into scientifically accepted ones. Case \& Fraser (1999) highlight

\footnotetext{
"Presented as an abstract for oral presentation at the International Conference on Education-ICE, 27-28 February 2014, Barcelona, Spain.

a Giresun University, Trabzon, Turkey. E-mail: mihrideniz61@gmail.com

${ }^{\mathrm{b}}$ Kırıkkale University, Kırıkkale, Turkey. E-mail: tugbrn@gmail.com

Corresponding Author: Figen Bozkuş, Kocaeli University, Faculty of Education, Kocaeli, Turkey. E-mail: figen.bozkuss@gmail.com
} 
that it is necessary to elaborate misconceptions in order to eliminate the misconceptions that students have or to achieve a conceptual transformation. There are some studies on mathematics education which reveal mathematical misconceptions. Some of them focus on the concept of symmetry, pointing out that students have difficulty in learning the concept of symmetry and develop many misconceptions (Aksoy \& Bayazit, 2010; Kaplan \& Öztürk, 2014; Köse, 2012).

Symmetry is one of the key concepts in geometry and underlies a number of mathematical concepts. Symmetry helps students in visualizing different geometric concepts and associating geometry learning with their real-life experiences (Leikin, Berman \& Zaslavsky, 2000). For that reason, it is one of the most significant application areas of mathematics. The concept of symmetry is essential not only in mathematics, but also in other disciplines such as physics, chemistry, music, design and geography (Leikin, Berman \& Zaslavsky, 1998; Leikin et al., 2000; Weyl, 1952). Students need the idea of symmetry so that they can effectively use the concept of symmetry in all these necessary areas. Therefore, mathematics educators emphasize that the concept of symmetry should be acquired by students at an early age (Aksoy \& Bayazit, 2010). Children develop the concept of symmetry informally from early ages (Köse, 2012). However, the studies show that students have difficulty in learning the concept of symmetry (Küchemann, 1981; Orton, 1999; Seidel, 1998; Hacısalihoğlu-Karadeniz, Baran, Bozkuş \& Gündüz, 2015). Zaslavsky (1994) reports that the difficulties that students have with the concept of symmetry are linked to the misconceptions of teachers in relation to symmetry. In this sense, in the relevant literature, there are some studies on the misconceptions of teachers in relation to the concept of symmetry (Leikin et al., 2000; Son, 2006).

Son (2006), in her study with teachers, reveals that teachers do not have sufficient knowledge on the concept of symmetry and do not know the properties of the concept of symmetry exactly. She concludes that some of the teachers reported a parallelogram has an axis of symmetry and some of them do not have sufficient conceptual knowledge on reflection symmetry. Further, she states that teachers, while teaching symmetry, have adopted a practical teaching process including mapping and folding strategies rather than conceptual knowledge. In a similar way, she finds out that teachers confused reflection and rotation symmetry and when teachers were asked to describe reflection symmetry, they actually defined rotation symmetry, and students, therefore, misunderstood these concepts as well. Similarly, Leikin et al. (2000) performed a study with prospective mathematics teachers, pointing out that the most common mistakes that they do are related to the axis of symmetry. They conclude that prospective teachers mostly think that the axis of the symmetry of a shape is the line that bisects it.

The relevant literature demonstrates that there are studies revealing misconceptions on the concept of symmetry for different age groups including elementary, middle school and high school students, prospective mathematics teachers and mathematics teachers (Hoyles \& Healy, 1997; Kaplan \& Öztürk, 2014; Köse \& Özdaş, 2009; Köse, 2012; Leikin et al., 2000; Son, 2006). Yet, there has not been enough research on the strategies that prospective teachers use while teaching reflection symmetry (Son, 2006). One of the objectives of this study is to determine the strategies that prospective teachers use in their teaching process, which is believed to be useful in addressing the gap in the literature. Moreover, the studies on symmetry in Turkey focus on primary and secondary school levels (Kaplan \& Öztürk, 2014; Köse \& Özdaş, 2009; Köse, 2012). In addition it is important that teachers should know common conceptions, misconceptions, and difficulties of students, and they should have the specific teaching strategies necessary to address students' learning needs in particular classroom circumstances (Son, 2006). Therefore, the present study is important in order to show how those who will soon become teachers will overcome the possible misconceptions and difficulties of students with reflective symmetry. For that reason, being performed with prospective mathematics teachers, this study will potentially add to the existing literature of Turkey. Given that, this study aims to reveal the explanations of the senior prospective middle school mathematics teachers for the potential misconceptions of students and the correction of such misconceptions.

\section{Method}

\section{Research Model}

Qualitative researchers focus their research on exploring, examining, and describing people and their natural environments (Orb, Eisenhauer, \& Wynaden, 2001). So this study is an exploratory study with a qualitative method, which examines the explanations of prospective middle school mathematics teachers for the concept of symmetry and other relevant conceptual and pedagogical reflections.

\section{Study Group}

This study was performed with a total of 26 senior prospective teachers in the Department of Middle School Mathematics Teaching at a university in the Region of Marmara in Turkey. The prospective teachers have completed the Special Teaching Methods I-II courses as part of the undergraduate program. These courses include the basic concepts of geometry and their relationships with field teaching, the analysis of curricula, the evaluation of course and student workbooks and teacher's books. The participants, further, had the opportunity to attend the practices in school and to observe classroom teaching activities. As per research ethics requirements, the participants were kept anonymous and identified as "'РT1", "РT2", "РT3", "РT4", "PT5", “PT6", "РT7"............" РT26."

\section{Data Collection Tool}

The data collection tool in the study was a test consisting of 6 open-ended questions. The test was prepared in line with the studies in the literature and the expert opinions on the definition of the concept of symmetry. Each question features similar examples to the drawings, the 
symmetries of which were wrongly formed by the participants at different levels in the literature. The right and wrong steps in forming the symmetric shape were asked next to the shapes; following that, if there is any wrong step taken, the way to correct them was asked to the participants. Although all of the symmetric shapes were wrong, the participants were asked to identify the right steps in order to make them give more-detailed answers. The participants were further asked to act as a teacher on the assumption that the wrong answers were provided by one of their students, and, thus, seeking to present more sound results. One of the questions in the data collection tool is given below (Figure 1).

The students have made certain mistakes in forming a symmetrical shape for the shapes below. Please explain the right and wrong steps of the students in forming a symmetrical shape in the first column and suggest what you can do to correct the misconception in the second column (The original shape is placed on the left side of the arrow and its reflection on the right side).

\begin{tabular}{l|l|l}
\hline & Right and Wrong Steps & The way to correct them \\
\cline { 2 - 3 }
\end{tabular}

Figure 1. A question used in the test

In order to ensure the reliability of the data collection tool, the test was firstly administered to a sample of 5 prospective teachers; following that, two researchers discussed the questions with these students and determined the questions which are incomprehensible or need to be more explanatory. In this way, one of the questions was excluded from the test, which consisted of 6 questions in the end. These questions were revised in line with the reflections of the prospective teachers in order to make them more comprehensible. The final version of the test was administered to the prospective teachers in classroom environment for a period of 40 minutes.

\section{Data Analysis}

The data, which were obtained from the test, were analyzed through descriptive analysis method in accordance with the purpose of the study. In descriptive analysis, the data are directly reported, remaining as unchanged as possible (Karadağ, 2010). The analysis of the data was carried out in two steps. First, the answers of the prospective teachers were independently analyzed by two researchers. In the analysis, researches organized the students' potential misconceptions and their explanations about how to overcome misconceptions and calculated the frequencies of the answers of the participants for the relevant sections. In the second step, the researchers came together to compare the analysis they have made, and after resolving the differences between analysis they decided the final version of the analysis. Thus, the reliability of analysis has been provided. As a result of the analysis, the answers of the participants for the relevant sections, along with the frequencies of the answers, were provided in tables. Furthermore, participants' answers to the open-ended questions in the test and their drawing representations were used to exemplify the misconceptions.

\section{Findings}

In the findings section, Tables demonstrates the opinions of the prospective teachers in regard to the identification of the right and wrong steps of students and the way to correct them. Following that, the explanations for each question and the examples from the answers of students were provided below. Moreover, the examples from the answers of the prospective teachers were presented for each question.

Table 1. The opinions related to first questions of the prospective teachers in regard to the identification of the right and wrong steps of students and the way to correct them

\begin{tabular}{|c|c|c|c|c|c|}
\hline \multirow[t]{2}{*}{ Figure } & \multicolumn{2}{|l|}{ Right and Wrong steps } & \multicolumn{2}{|c|}{ The way to correct them $(f)$} & \multirow{2}{*}{$\begin{array}{l}\text { Not finding solution } \\
(f) \\
3\end{array}$} \\
\hline & $\begin{array}{l}\text { Angle of symmetry axis not } \\
\text { accounted }\end{array}$ & 21 & $\begin{array}{l}\text { Make the rules of } \\
\text { symmetry revised }\end{array}$ & 12 & \\
\hline & $\begin{array}{l}\text { Distances to symmetry axis } \\
\text { taken wrongly }\end{array}$ & 4 & $\begin{array}{l}\text { Take attention on } \\
\text { symmetry axis }\end{array}$ & 6 & \\
\hline & $\begin{array}{l}\text { Instructed deficiently in the } \\
\text { courses }\end{array}$ & 1 & $\begin{array}{l}\text { Symmetrise via } \\
\text { paper folding }\end{array}$ & 2 & \\
\hline & Knowledge memorized & 1 & $\begin{array}{l}\text { Make use of } \\
\text { computer software }\end{array}$ & 2 & \\
\hline & Symmetrised on $x$ axis & 1 & $\begin{array}{l}\text { Give examples from } \\
\text { daily life }\end{array}$ & 1 & \\
\hline & Same of the shape taken & 1 & & & \\
\hline
\end{tabular}




\section{Findings concerning the first question}

In the above question, the angle of symmetry axis is given as the narrow angle. But the answer of a student, presumed to neglect the axis of the symmetry, was provided in the first question to the prospective teachers. The majority of them ( $\mathrm{PT}_{1}, \mathrm{PT}_{3}, \mathrm{PT}_{4}, \mathrm{PT}_{5}, \mathrm{PT}_{7}, \mathrm{PT}_{9}, \mathrm{PT}_{10}, \mathrm{PT}_{11}$, $\mathrm{PT}_{12}, \mathrm{PT}_{14}, \mathrm{PT}_{15}, \mathrm{PT}_{16}, \mathrm{PT}_{17}, \mathrm{PT}_{18}, \mathrm{PT}_{19}, \mathrm{PT}_{20}, \mathrm{PT}_{21}, \mathrm{PT}_{22}, \mathrm{PT}_{24}$, $\mathrm{PT}_{25}, \mathrm{PT}_{26}$ ) were aware of such mistake. One of them stated that: "The axis was considered to be straight rather than inclined. The symmetrical shape was formed based on that... $\mathrm{PT}_{3}{ }^{\prime \prime} \mathrm{A}$ total of four prospective teachers reported that it is related to the distance to the axis of the symmetry, which is not calculated accurately, rather than the neglection of the angle of the axis of the symmetry $\left(\mathrm{PT}_{2}, \mathrm{PT}_{6}, \mathrm{PT}_{8}, \mathrm{PT}_{13}\right)$. The opinion of $\mathrm{PT}_{2}$ is as follows: "The most important feature in symmetry is position. The distance to the axis of symmetry should be the same to the distance to the reflection." Considering the prospective teachers with similar opinions, they were partially able to explain the mistake. These prospective teachers could not acknowledge that the axis of the symmetry was considered to be the vertical axis, but its angle was different from the right angle. One of them stated that the concept of symmetry might have been poorly taught in the courses probably with regards to content $\left(\mathrm{PT}_{10}\right)$ and the students might have memorized the concept of symmetry $\left(\mathrm{PT}_{1}\right)$ and, thus, pointed out a lack in learningteaching process. On the other hand, $\mathrm{PT}_{12}$ reported that the symmetrical shape was formed based on the axis and $\mathrm{PT}_{23}$ said that the symmetrical shape to be formed was the same with that in the right on the axis of the symmetry, and they themselves fell into a misconception while they were supposed to report the difficulty that the student had. One of these prospective teachers stated that "It is a wrong step. The symmetrical shape was formed based on $\mathrm{x}$-axis... $\mathrm{PT}_{21}{ }^{\prime \prime}$

When the way to correct the mistakes that the prospective teachers identified was asked to them, most of them tended to give more general answers, instead of specific answers for the mistakes of the students. In the first question, almost half of the prospective teachers (PT1, $\mathrm{PT}_{4}, \mathrm{PT}_{5}, \mathrm{PT}_{6}, \mathrm{PT}_{8}, \mathrm{PT}_{12}, \mathrm{PT}_{13}, \mathrm{PT}_{14}, \mathrm{PT}_{15}, \mathrm{PT}_{17}, \mathrm{PT}_{24}, \mathrm{PT}_{26}$ ) provided a very general answer by stating that "I would make the student repeat the rules of symmetry." One of these prospective teachers expressed his/her opinion as follows: "I would ask the student to draw a perpendicular to every point in the shape based on the axis of the symmetry and to mark the same vertical distance (as a point) on the other side of the shape, then, to combine these points... $\mathrm{PT}_{1}$ " A total of 6 prospective teachers PT $_{7}$, $\mathrm{PT}_{9}, \mathrm{PT}_{10}, \mathrm{PT}_{11}, \mathrm{PT}_{22}, \mathrm{PT}_{25}$ ) stated that they would point out the axis of the symmetry. The specific answer for the mistake was provided by $\mathrm{PT}_{7}$, who reported that "I would ask the student to form the symmetrical shape when it is vertical, and show that it would not be the same with the symmetrical shape formed when the axis is inclined." A total of 5 prospective teachers tended to give more general answers rather than specific ones by saying that they would form the symmetrical shape by means of folding $\left(\mathrm{PT}_{3}, \mathrm{PT}_{18}\right)$, they would use computer software $\left(\mathrm{PT}_{20}, \mathrm{PT}_{21}\right)$ and they would provide examples from daily life. The answers of some of these prospective teachers are as follows: "I would ask the student to fold the paper over the axis of the symmetry, and make him/her realize that the resulting shape is the symmetrical shape... $\mathrm{PT}_{18}{ }^{\prime \prime}$ and "It is possible to concretize the information via computer software, e.g. Geogebra..." Notably, the answers of some of the prospective teachers $\left(\mathrm{PT}_{16}, \mathrm{PT}_{19}, \mathrm{PT}_{23}\right)$ did not focus on finding solutions to the mistake. Among them, there was the answer of $\mathrm{PT}_{16}$, which is that "the answer would be right if it was formed based on the inclination of the axis of symmetry" and the answer of $\mathrm{PT}_{19}$, which is that "the mistake can be corrected if the axis of symmetry is considered to be y-axis."

Table 2. The opinions related to second questions of the prospective teachers in regard to the identification of the right and wrong steps of students and the way to correct them

\begin{tabular}{|c|c|c|c|c|c|}
\hline Figure & Right and Wrong steps & & The way to correct them $(f)$ & & $\begin{array}{ll}\text { Not finding } \\
\text { solution }(f)\end{array}$ \\
\hline \multirow{10}{*}{$\begin{array}{l}\mathbf{N} \\
\mathbf{z} \\
\text { o } \\
\text { 管 } \\
\text { o }\end{array}$} & Shape drawn completely mistakenly & 9 & Make the rules of symmetry revised & 13 & 5 \\
\hline & Completed into triangle & 8 & Symmetrise via paper folding & 5 & \\
\hline & Couldn't get symmetrised & 6 & Do much exercise & 2 & \\
\hline & Not knowing what symmetry means & 3 & Make use of unit square & 1 & \\
\hline & Symmetry axis taken wrongly & 2 & Use mirrors & 1 & \\
\hline & Some shapes cannot be symmetrised & 1 & Display in reverse & 1 & \\
\hline & Main shape is wrong & 1 & Make use of computer software & 1 & \\
\hline & A symmetry axis in both sides required & 1 & Give examples from daily life & 1 & \\
\hline & Shape not having symmetry line & 1 & Display shapes unsymmetrised & 1 & \\
\hline & Could not understand what was done & 1 & & & \\
\hline
\end{tabular}




\section{Findings concerning the second question}

In the second question, the prospective teachers were asked to reflect on the practice of completing the shape, which is one of the common misconceptions of students in relation to the concept of symmetry in the literature. It is remarkable that most of the prospective teachers provided general answers and could not fully explain the mistake. The most common general answer given by the prospective teachers was that the assumed student formed a completely wrong symmetrical shape $\left(\mathrm{PT}_{3}, \mathrm{PT}_{4}\right.$, $\left.\mathrm{PT}_{5}, \mathrm{PT}_{18}, \mathrm{PT}_{19}, \mathrm{PT}_{20}, \mathrm{PT}_{21}, \mathrm{PT}_{22}, \mathrm{PT}_{23}\right)$. One of these prospective teachers expressed that "Every step is wrong... $\mathrm{PT}_{18}$ " Only 8 of 26 prospective teachers identified the mistake and stated that the student completed the triangle $\left(\mathrm{PT}_{1}, \mathrm{PT}_{5}, \mathrm{PT}_{6}, \mathrm{PT}_{7}, \mathrm{PT}_{9}, \mathrm{PT}_{11}, \mathrm{PT}_{14}, \mathrm{PT}_{16}\right)$. One of them stated that "the student attempted to complete the shape rather than forming a symmetrical shape... $\mathrm{PT}_{11}$ " A total of 6 prospective teachers provided a general answer, reporting that a symmetrical shape was not formed $\left(\mathrm{PT}_{4}\right.$, $\left.\mathrm{PT}_{11}, \mathrm{PT}_{12}, \mathrm{PT}_{15}, \mathrm{PT}_{17}, \mathrm{PT}_{24}\right) . \mathrm{PT}_{15}$ said that "A symmetrical shape was not formed based on the axis, but I did not understand what the student did", emphasizing that the operation was not accurate, but failed to explain why it was not. Some of the prospective teachers ( $\mathrm{PT}_{9}, \mathrm{PT}_{10}, \mathrm{PT}_{26}$ ) claimed that the student who was presumed to make such mistake did not know the concept of symmetry. One of these prospective teachers stated that "The axis of symmetry and the concept of reflection have not been sufficiently understood; therefore, this shape has nothing to do with a symmetrical shape... $\mathrm{PT}_{26}$ " Many prospective teachers themselves fell into a misconception, reporting that the axis of symmetry was wrongly taken $\left(\mathrm{PT}_{2}, \mathrm{PT}_{8}\right)$, that it is not possible to form a symmetrical shape for some shapes $\left(\mathrm{PT}_{25}\right)$, that the original shape is inaccurate $\left(\mathrm{PT}_{24}\right)$, that there should have been an axis of symmetry where the shape would be the same on the both sides $\left(\mathrm{PT}_{22}\right)$ and that the shape does not have a symmetry line. The answers of several of these prospective teachers were as follows: "The axis of symmetry was wrongly considered...PT ${ }_{2}$ ", "When the shape is folded over the axis of symmetry, the parts do not overlap each other... The original shape is inaccurate... $\mathrm{PT}_{24}$ ", "The shape does not have a symmetry line... $\mathrm{PT}_{13}$ ". One of the prospective teachers did not understand what the student had done and also the underlying reason for the mistake ( $\left.\mathrm{PT}_{15}\right)$.

The prospective teachers mostly provided general answers to the question regarding the way to correct the mistake/mistakes in the second question. In this question, as in the first question, many prospective teachers $\left(\mathrm{PT}_{1}\right.$, $\mathrm{PT}_{3}, \mathrm{PT}_{5}, \mathrm{PT}_{6}, \mathrm{PT}_{7}, \mathrm{PT}_{9}, \mathrm{PT}_{10}, \mathrm{PT}_{11}, \mathrm{PT}_{12}, \mathrm{PT}_{14}, \mathrm{PT}_{20}, \mathrm{PT}_{23}, \mathrm{PT}_{24}$ ) stated that they would make the student repeat the rules of symmetry in order to correct the mistake. The general answers, which were given in the first question, such as "I would form the symmetrical shape by means of folding" ( $\mathrm{PT}_{13}, \mathrm{PT}_{15}, \mathrm{PT}_{19}, \mathrm{PT}_{22}, \mathrm{PT}_{24}$ ), "I would use computer software" ( $\left.\mathrm{PT}_{3}\right)$ and "I would give examples from daily life" $\left(\mathrm{PT}_{26}\right)$, as well as the answers such as "I would make the student practice more often" $\left(\mathrm{PT}_{21}, \mathrm{PT}_{26}\right)$, "I would use unit squares" ( $\left.\mathrm{PT}_{20}\right)$ and "I would use a mirror" $\left(\mathrm{PT}_{20}\right)$ Among such general answers, there were the following answers:
"It is necessary to practice often. The exercises in the textbook should be completed. We should make them complete the exercises in the workbook... $\mathrm{PT}_{21}$ ", "These concepts should be explained in detail through the examples from daily life. We should make students solve plenty of similar exercises... $\mathrm{PT}_{26}{ }^{\prime \prime}$ While $\mathrm{PT}_{4}$ attempted to provide a solution and reported that "As the student drew the shape on the line, I would show that the shape is drawn on the right of the axis of symmetry while the symmetrical shape is formed on the left side." $\mathrm{PT}_{25}$ gave an inaccurate answer resulting from her/his own misconception by stating that "I would help the student by showing other shapes for which no symmetrical shape can be formed." A total of 5 prospective teachers $\left(\mathrm{PT}_{2}, \mathrm{PT}_{8}\right.$, $\mathrm{PT}_{16}, \mathrm{PT}_{17}, \mathrm{PT}_{25}$ ) provided some suggestions, which could not be considered as a solution. One of them, $\mathrm{PT}_{16}$, stated that "The idea to complete the shape should be eliminated and the idea to form a symmetrical shape should be considered." Further, $\mathrm{PT}_{8}$ drew the following shape (Figure 2) to provide a solution.

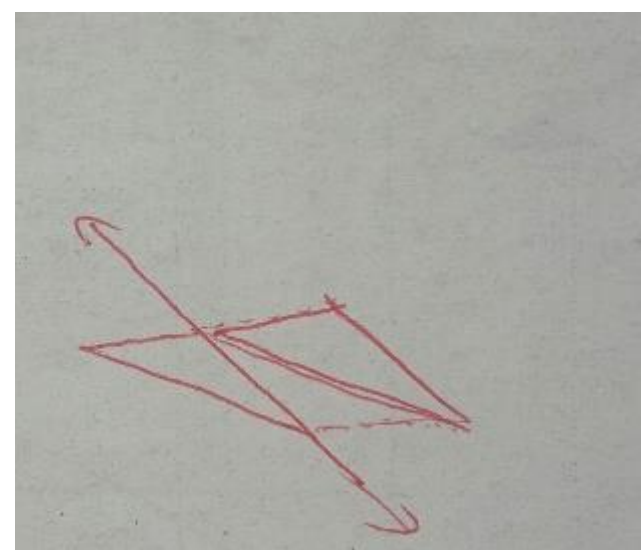

Figure 2. The drawing of $\mathrm{PT}_{8}$ for the solution of the mistake in the $2^{\text {nd }}$ question

\section{Findings concerning the third question}

In the third question, the prospective teachers were asked to identify a mistake of a student, who was supposed to form the symmetrical shape consisting of the letters of the word "KITAP" only based on the vertical axis, but rather formed the symmetrical shape based on the horizontal axis as well. Almost half of the prospective teachers stated that the student overgeneralized the rule $\left(\mathrm{PT}_{1}, \mathrm{PT}_{2}, \mathrm{PT}_{3}, \mathrm{PT}_{4}, \mathrm{PT}_{8}, \mathrm{PT}_{9}, \mathrm{PT}_{11}, \mathrm{PT}_{12}, \mathrm{PT}_{13}, \mathrm{PT}_{14}, \mathrm{PT}_{16}, \mathrm{PT}_{24}\right.$ ) and provided a general, but an accurate explanation. One of these prospective teachers reported that "The student formed both a symmetrical shape and a reverse shape... $\mathrm{PT}_{11}$ " A total of 4 prospective teachers $\left(\mathrm{PT}_{5}, \mathrm{PT}_{15}, \mathrm{PT}_{18}, \mathrm{PT}_{19}\right.$ ) rightly stated that the student, who was assumed to make the mistake, formed a symmetrical shape based on both the horizontal and vertical axis. The opinion of $\mathrm{PT}_{18}$ was as follows: "The symmetrical shape was formed both on the horizontal and the vertical axis." Some of the prospective teachers $\left(\mathrm{PT}_{9}, \mathrm{PT}_{10}, \mathrm{PT}_{25}\right)$, similar to the previous opinion, reported that the student formed a symmetrical shape based on the origin, rather than the vertical axis. $\mathrm{PT}_{6}, \mathrm{PT}_{12}$, 
$\mathrm{PT}_{25}$ stated that the student partially knew the concept of symmetry. With such opinion, $\mathrm{PT}_{12}$ reflected that "They wrote the word in reverse while forming the symmetrical shape. Yet, it is obvious that they partially know something as the letter close to the axis of symmetry is close to the axis of symmetry in the symmetrical shape as well." A total of 3 prospective teachers ( $\mathrm{PT}_{17}, \mathrm{PT}_{20}, \mathrm{PT}_{23}$ ) stated that the direction of the symmetrical shape is not accurate and thus provided a general answer. One of these participants reported that "The order of the letters is accurate, but the direction should be kept same... $\mathrm{PT}_{17}{ }^{\prime \prime}$ but failed to explain what he/she meant by the direction. This is the same case for the other prospective teachers with the same opinion. A total of 2 prospective teachers, who said that the student considered the axis of symmetry as horizontal $\left(\mathrm{PT}_{7}, \mathrm{PT}_{26}\right)$, and one of the prospective teachers, who reported that the student formed the symmetrical shape based on y-axis, rather than $\mathrm{x}$-axis, $\left(\mathrm{PT}_{21}\right)$ fell into a misconception. $\mathrm{PT}_{7}$ stated that "the operation was performed based on a horizontal axis of symmetry", which is one of the examples of the misconceptions. Further, $\mathrm{PT}_{22}$ failed to fully explain the mistake by reporting that "The right step is that the distance is not the same, but close. The wrong thing is to complete the shape in a reverse manner due to the lack of points."

Table 3. The opinions related to third questions of the prospective teachers in regard to the identification of the right and wrong steps of students and the way to correct them

\begin{tabular}{|c|c|c|c|c|c|c|}
\hline \multicolumn{2}{|c|}{ Figure } & \multicolumn{2}{|l|}{ Right and Wrong steps } & \multicolumn{2}{|l|}{ The way to correct them $(f)$} & \multirow{2}{*}{$\begin{array}{c}\text { Not finding } \\
\text { solution }(f) \\
8\end{array}$} \\
\hline \multirow{7}{*}{ KITAP } & \multirow{7}{*}{$d \forall \perp ! \mid$} & Overgeneralization & 12 & $\begin{array}{l}\text { Make the rules of } \\
\text { symmetry revised }\end{array}$ & 7 & \\
\hline & & $\begin{array}{l}\text { Symmetrised on vertical and } \\
\text { horizontal axis }\end{array}$ & 4 & $\begin{array}{l}\text { Symmetrise via paper } \\
\text { folding }\end{array}$ & 6 & \\
\hline & & Symmetrised on origin & 3 & Use mirrors & 6 & \\
\hline & & Partly knows about symmetry & 3 & Do much exercise & 2 & \\
\hline & & Directions wrong & 3 & $\begin{array}{l}\text { Simultaneous feedback on } \\
\text { the error }\end{array}$ & 1 & \\
\hline & & Symmetry axis taken horizontally & 2 & Make visual discourse & 1 & \\
\hline & & $\begin{array}{l}\text { Symmetrised on } y \text { axis but not on } \\
x \text { axis }\end{array}$ & 1 & & & \\
\hline
\end{tabular}

It is notable that the number of the prospective teachers, who failed to provide a solution for the mistake in the third question, is higher than in other questions $\left(\mathrm{PT}_{2}, \mathrm{PT}_{5}\right.$, $\left.\mathrm{PT}_{8}, \mathrm{PT}_{11}, \mathrm{PT}_{15}, \mathrm{PT}_{16}, \mathrm{PT}_{18}, \mathrm{PT}_{23}\right)$. The answers of some of these prospective teachers were as follows: "The letters except for $\mathrm{K}$ should be reversed (on the right) and $\mathrm{d}$ should be replaced by q... $\mathrm{PT}_{2}$ ", "The student should realize that the symmetrical shape is formed only based on the vertical axis... $\mathrm{PT}_{5}{ }^{\prime \prime}$ The suggestions for the mistake in the third question are general similar to the suggestions in other questions. A total of 7 prospective teachers ( $\left.\mathrm{PT}_{1}, \mathrm{PT}_{2}, \mathrm{PT}_{7}, \mathrm{PT}_{9}, \mathrm{PT}_{10}, \mathrm{PT}_{19}, \mathrm{PT}_{25}\right)$ argued that the rules of symmetry should be repeated to correct the mistake whereas a total of 6 prospective teachers ( $\mathrm{PT}_{3}$, $\mathrm{PT}_{14}, \mathrm{PT}_{20}, \mathrm{PT}_{21}, \mathrm{PT}_{22}, \mathrm{PT}_{24}$ ) thought that the method of paper folding would be useful. Some of the prospective teachers ( $\mathrm{PT}_{1}, \mathrm{PT}_{3}, \mathrm{PT}_{4}, \mathrm{PT}_{6}, \mathrm{PT}_{17}, \mathrm{PT}_{26}$ ) often reported that the use of a mirror would be useful in teaching the concept of symmetry. One of these prospective teachers stated that "I would write the word ITFAiYE on the board and ask the student to reflect it with a mirror. Upon seeing the reflection, the misconception of the student will be clarified... $\mathrm{PT}_{26}$ " While there were some prospective teachers who argued that more practice would be useful $\left(\mathrm{PT}_{9}, \mathrm{PT}_{10}\right)$, one of the prospective teachers $\left(\mathrm{PT}_{12}\right)$ stated that it is possible to correct the mistake of the student by giving immediate feedback. On the other hand, $\mathrm{PT}_{13}$ reported that "Explaining the subject in a visual manner would prevent such mistake" and thus emphasized the usefulness of visual expression, but failed to state what he/she meant by visuality.

\section{Findings concerning the fourth question}

In the fourth question, the prospective teachers were asked to evaluate the answer of a student, who was assumed to write the letters back to front while forming the symmetrical shape for the word "KITAP" based on the vertical axis. $\mathrm{PT}_{3}, \mathrm{PT}_{5}, \mathrm{PT}_{6}, \mathrm{PT}_{15}, \mathrm{PT}_{17}, \mathrm{PT}_{18}, \mathrm{PT}_{20}, \mathrm{PT}_{21}, \mathrm{PT}_{22}$, $\mathrm{PT}_{26}$ reported that the student failed to form the reverse image of the letters. One of these prospective teachers (PT5) stated that "The order of the letters is accurate, but their direction is inaccurate." A total of 8 prospective teachers ( $\mathrm{PT}_{7}, \mathrm{PT}_{9}, \mathrm{PT}_{11}, \mathrm{PT}_{13}, \mathrm{PT}_{14}, \mathrm{PT}_{16}, \mathrm{PT}_{19}, \mathrm{PT}_{23}$ ) described the mistake of the student and reported that the word was written in reverse. One of the prospective teachers stated that "The student wrote the text in reverse... $\mathrm{PT}_{19}$ " Some of the prospective teachers ( $\mathrm{PT}_{1}$, $\mathrm{PT}_{10}, \mathrm{PT}_{13}, \mathrm{PT}_{25}$ ) provided a general explanation by stating that the student did not follow the rules of symmetry. PT reflected that "The letters are in order, but the rules of 
symmetry have not been followed." Similar to other answers in several questions, the answer which was "the student does not know fully the concept", was also given to this question as well $\left(\mathrm{PT}_{9}, \mathrm{PT}_{10}, \mathrm{PT}_{22}\right)$. Moreover, two prospective teachers $\left(\mathrm{PT}_{4}, \mathrm{PT}_{11}\right)$ stated that the student had a misconception. $\mathrm{PT}_{24}$ reported that "the distance between the letters is accurate, but they are wrongly placed" whereas $\mathrm{PT}_{12}$ reflected that "While forming the symmetrical shape, the distance of a point to the axis of symmetry should be the same with the distance of the symmetrical shape and the axis of symmetry."

Table 4. The opinions related to fourth questions of the prospective teachers in regard to the identification of the right and wrong steps of students and the way to correct them

\begin{tabular}{|c|c|c|c|c|c|}
\hline Figure & Right and Wrong steps & $f$ & The way to correct them & $f$ & $\begin{array}{l}\text { Not finding } \\
\text { solution }(f)\end{array}$ \\
\hline \multirow{8}{*}{ KITAP $:$ PATIK } & $\begin{array}{l}\text { Reverse image of letters not } \\
\text { taken }\end{array}$ & 10 & Make the rules of symmetry revised & 12 & 4 \\
\hline & Word written reversely & 8 & Use mirrors & 7 & \\
\hline & Symmetry rules not followed & 4 & & 4 & \\
\hline & Not learnt the concept sufficiently & 3 & Do much exercise & 3 & \\
\hline & Misconception & 2 & Symmetrise via paper folding & 2 & \\
\hline & Spelling error & 1 & $\begin{array}{l}\text { Simultaneous feedback on the } \\
\text { error }\end{array}$ & 1 & \\
\hline & & & Make use of checkered paper & 1 & \\
\hline & Distances mistaken & 1 & $\begin{array}{l}\text { Maket hem use thread or potate } \\
\text { print }\end{array}$ & 1 & \\
\hline
\end{tabular}

It is remarkable that the suggestions for correcting the mistake of the student, who was assumed to spell the word in reverse in the fourth question, focused on making the student repeat the rules of symmetry $\left(\mathrm{PT}_{1}, \mathrm{PT}_{2}, \mathrm{PT}_{4}\right.$, $\mathrm{PT}_{8}, \mathrm{PT}_{9}, \mathrm{PT}_{11}, \mathrm{PT}_{12}, \mathrm{PT}_{14}, \mathrm{PT}_{17}, \mathrm{PT}_{18}, \mathrm{PT}_{22}, \mathrm{PT}_{24}$ ). A total of 7 prospective teachers $\left(\mathrm{PT}_{3}, \mathrm{PT}_{5}, \mathrm{PT}_{9}, \mathrm{PT}_{14}, \mathrm{PT}_{15}, \mathrm{PT}_{17}, \mathrm{PT}_{19}\right.$ ) stated that it is possible to correct the mistake by using a mirror. Some prospective teachers suggested that the student should solve more problems $\left(\mathrm{PT}_{13}, \mathrm{PT}_{17}, \mathrm{PT}_{26}\right)$, find out the symmetrical shape by means of paper folding $\left(\mathrm{PT}_{3}, \mathrm{PT}_{20}\right)$ whereas one of the prospective teachers argued that the student should use a plotting paper ( $\left.\mathrm{PT}_{10}\right)$ and one of them claimed that it is possible to overcome such mistake through immediate feedback $\left(\mathrm{PT}_{7}\right) . \mathrm{PT}_{21}$ gave a different answer and suggested or rope printing, but did not provide any detail. A total of 4 prospective teachers $\left(\mathrm{PT}_{6}, \mathrm{PT}_{15}, \mathrm{PT}_{23}, \mathrm{PT}_{25}\right)$ provided confusing rather than solution-oriented suggestions. The following suggestions might indicate such confusion: "I would ask why the reflecting letters would not be reversed with the word... $\mathrm{PT}_{25}$ " and "I would say that the letters at the both sides are to face towards the mirror... $\mathrm{PT}_{6}{ }^{\prime \prime}$

Table 5. The opinions related to fifth questions of the prospective teachers in regard to the identification of the right and wrong steps of students and the way to correct them

\begin{tabular}{|c|c|c|c|c|c|}
\hline \multirow[t]{8}{*}{ Figure } & \multicolumn{2}{|l|}{ Right and Wrong steps $(f)$} & \multicolumn{2}{|l|}{ The way to correct them $(f)$} & \multirow{2}{*}{$\begin{array}{c}\text { Not finding solution }(f) \\
2\end{array}$} \\
\hline & $\begin{array}{l}\text { Distances to the axis not } \\
\text { accounted }\end{array}$ & 14 & $\begin{array}{l}\text { Make the rules of symmetry } \\
\text { revised }\end{array}$ & 17 & \\
\hline & Reflection not taken & 10 & $\begin{array}{l}\text { Tell the diference between } \\
\text { translation \& symmetry }\end{array}$ & 3 & \\
\hline & Translation done & 6 & Use mirrors & 2 & \\
\hline & Misconception & 5 & & 2 & \\
\hline & & & Make use of checkered paper & 1 & \\
\hline & Same of the shape taken & 5 & Use question answer method & 1 & \\
\hline & & & Tell axis concept & 1 & \\
\hline
\end{tabular}

\section{Findings concerning the fifth question}

In this question, the participants were asked to evaluate the answer of a student, who inaccurately calculated the distance of the symmetrical shape to the axis of symmetry and formed the same shape in the other side of the axis of symmetry. More than half of the prospective teachers ( $\mathrm{PT}_{1}, \mathrm{PT}_{2}, \mathrm{PT}_{5}, \mathrm{PT}_{8}, \mathrm{PT}_{13}, \mathrm{PT}_{15}, \mathrm{PT}_{17}, \mathrm{PT}_{18}, \mathrm{PT}_{19}, \mathrm{PT}_{20}$, $\mathrm{PT}_{22}, \mathrm{PT}_{23}, \mathrm{PT}_{24}, \mathrm{PT}_{26}$ ) stated that the distance of the symmetrical shape to the axis of symmetry was inaccurately calculated. A total of 10 prospective teachers 
$10\left(\mathrm{PT}_{3}, \mathrm{PT}_{4}, \mathrm{PT}_{5}, \mathrm{PT}_{9}, \mathrm{PT}_{18}, \mathrm{PT}_{20}, \mathrm{PT}_{21}, \mathrm{PT}_{22}, \mathrm{PT}_{25}, \mathrm{PT}_{26}\right.$ ) reported that the student failed to form a reflection on the right side of the axis of symmetry. In a similar way, a total of 5 prospective teachers $\left(\mathrm{PT}_{5}, \mathrm{PT}_{6}, \mathrm{PT}_{12}, \mathrm{PT}_{16}, \mathrm{PT}_{24}\right.$ ) stated that the student attempted to form a symmetrical shape by keeping the shape same. Based on the answers of the prospective teachers, it is notable that there is only a total of 6 prospective teachers who pointed out both of the mistakes ( $\left.\mathrm{PT}_{5}, \mathrm{PT}_{18}, \mathrm{PT}_{20}, \mathrm{PT}_{22}, \mathrm{PT}_{24}, \mathrm{PT}_{26}\right)$. Referring to both of the mistakes, one of them reported that: "It is inaccurate. The symmetry of the shape is not positioned in the equal distance and the direction of the shape is different... $\mathrm{PT}_{20}$ " On the other hand, $\mathrm{PT}_{7}, \mathrm{PT}_{9}, \mathrm{PT}_{10}, \mathrm{PT}_{11}$, $\mathrm{PT}_{14}, \mathrm{PT}_{21}$ stated that the student displaced the shape although he/she was supposed to reflect it. PT11 reflected on the mistake and said that "The student may have confused it with translation." A total of 5 prospective teachers $\left(\mathrm{PT}_{6}, \mathrm{PT}_{9}, \mathrm{PT}_{10}, \mathrm{PT}_{11}, \mathrm{PT}_{12}\right)$ reported that the student has a misconception. One of these prospective teachers stated that: "The student assumed that the symmetrical shape is the same with the original shape... $\mathrm{PT}_{6}^{\prime \prime}$

The vast majority of the prospective teachers $\left(\mathrm{PT}_{1}, \mathrm{PT}_{2}\right.$, $\mathrm{PT}_{3}, \mathrm{PT}_{4}, \mathrm{PT}_{5}, \mathrm{PT}_{6}, \mathrm{PT}_{9}, \mathrm{PT}_{10}, \mathrm{PT}_{12}, \mathrm{PT}_{13}, \mathrm{PT}_{15}, \mathrm{PT}_{16}, \mathrm{PT}_{17}, \mathrm{PT}_{22}$,
$\mathrm{PT}_{23}$ ) argued that repeating the rules of symmetry would help the student correct the mistake. One of these prospective teachers reported that: "The misconception here is that the shape was written same and the distance to the line in the drawing was not the same. It is obvious that the student does not understand anything about symmetry. I would give the lecture again :))...PT ${ }_{4}$ " The answers of a total of 3 prospective teachers $\left(\mathrm{PT}_{11}, \mathrm{PT}_{14}\right.$, $\mathrm{PT}_{21}$ ) were directly related to the mistake; their answer was "I would tell the difference between translation and symmetry." There are 2 prospective teachers ( $\left.\mathrm{PT}_{18}, \mathrm{PT}_{19}\right)$ who stated that they could correct the mistake by using a mirror. In order to correct it, $\mathrm{PT}_{20}$ suggested the use of a plotting paper whereas $\mathrm{PT}_{7}$ suggested a question and answer method. $\mathrm{PT}_{26}$ highlighted the importance of the concept of the axis of symmetry and stated that: "It is necessary to explain the concept of axis in detail. Students should particularly solve the problems involving the reflection of line segments." A total of 2 prospective teachers $\left(\mathrm{PT}_{8}, \mathrm{PT}_{21}\right)$ failed to suggest any solution. For instance, $\mathrm{PT}_{21}$ simply described the mistake and reported that: "We should differentiate between translation and symmetry."

Table 6. The opinions related to sixth questions of the prospective teachers in regard to the identification of the right and wrong steps of students and the way to correct them

\begin{tabular}{|c|c|c|c|c|c|}
\hline Figure & Right and Wrong steps & $f$ & The way to correct them & $f$ & $\begin{array}{l}\text { Not finding } \\
\text { solution }(f)\end{array}$ \\
\hline & Ordering mistake & 13 & $\begin{array}{l}\text { Make the rules of symmetry } \\
\text { revised }\end{array}$ & 10 & 2 \\
\hline & $\begin{array}{l}\text { Distances to symmetry axis } \\
\text { wrong }\end{array}$ & 11 & Use mirorrs & 6 & \\
\hline & Directions taken correctly & 3 & Use watch & 3 & \\
\hline & $\begin{array}{l}\text { Hour and minute taken } \\
\text { seperately }\end{array}$ & 2 & Symmetrise via paper folding & 3 & \\
\hline & Not sym & & & & \\
\hline & metrised on mirror & 2 & Make visual discourse & 1 & \\
\hline & Misconception & 2 & Make use of computer software & 1 & \\
\hline & $\begin{array}{l}\text { Not knowing what symmetry } \\
\text { means }\end{array}$ & 1 & Use question answer method & 1 & \\
\hline & Not symmetrised but taken & 1 & Solve on the board & 1 & \\
\hline & digits & 1 & Not answering & 1 & \\
\hline & Not answering & 1 & & & \\
\hline
\end{tabular}

\section{Findings concerning the sixth question}

In the sixth question, the participants were asked to identify the wrong and right steps in an example where the student accurately formed the reflection of a digital clock by taking into consideration each number, but confused the placement of the hours and minutes. Half of the prospective teachers $\left(\mathrm{PT}_{1}, \mathrm{PT}_{3}, \mathrm{PT}_{8}, \mathrm{PT}_{9}, \mathrm{PT}_{13}, \mathrm{PT}_{14}, \mathrm{PT}_{15}\right.$,
$\mathrm{PT}_{17}, \mathrm{PT}_{20}, \mathrm{PT}_{23}, \mathrm{PT}_{24}, \mathrm{PT}_{25}, \mathrm{PT}_{26}$ ) emphasized the mistake about the placement. In this regard, PT13 stated that "It should be 22:13; the placement is wrong." A total of 11 prospective teachers $\left(\mathrm{PT}_{2}, \mathrm{PT}_{5}, \mathrm{PT}_{7}, \mathrm{PT}_{10}, \mathrm{PT}_{11}, \mathrm{PT}_{12}, \mathrm{PT}_{18}\right.$, $\mathrm{PT}_{19}, \mathrm{PT}_{22}, \mathrm{PT}_{25}, \mathrm{PT}_{26}$ ) stated that the distance to the axis of symmetry was inaccurate. One of these prospective teachers reflected on the mistake: "It is completely wrong. 
The distance to the mirror is important when it comes to symmetry... $\mathrm{PT}_{2}$ " On the other

hand, $\mathrm{PT}_{20}, \mathrm{PT}_{22}, \mathrm{PT}_{26}$ stated that only the direction was right and failed to report that the placement was wrong. From this point of view, there is only one prospective teacher $\left(\mathrm{PT}_{26}\right)$ who precisely pointed out the mistake in the question. $\mathrm{PT}_{26}$ said that: "The symmetry of the shapes was correct, but the distance and placement to the axis was neglected."

A total of 2 prospective teachers $\left(\mathrm{PT}_{7}, \mathrm{PT}_{25}\right)$ reported that the student considered the hour and the minutes separately; one of them stated that: "The student considered the hour and the minutes separately. Their distance to the axis of symmetry was wrong... $\mathrm{PT}_{7}$ " A total of 4 prospective teachers tended to provide more general answers and reported that the symmetrical shape was not formed based on the mirror $\left(\mathrm{PT}_{16}, \mathrm{PT}_{17}\right)$ and there is a misconception $\left(\mathrm{PT}_{4}, \mathrm{PT}_{12}\right)$. For instance, "This symmetrical shape was not formed based on the mirror...PT ${ }_{16}$ " On the other hand, $\mathrm{PT}_{6}$ failed to provide an answer; $\mathrm{PT}_{21}$ stated that the student does not know the concept of symmetry and $\mathrm{PT}_{4}$ reported that the student, unable to form a symmetrical shape, simply wrote the figures in reverse.

Lastly, nearly half of the prospective teachers $\left(\mathrm{PT}_{2}, \mathrm{PT}_{3}\right.$ $\mathrm{PT}_{4}, \mathrm{PT}_{6}, \mathrm{PT}_{12}, \mathrm{PT}_{15}, \mathrm{PT}_{22}, \mathrm{PT}_{23}, \mathrm{PT}_{24}, \mathrm{PT}_{26}$ ) stated that they would make the student repeat the rules of symmetry in order to correct the mistake in the sixth question. A total of 6 prospective teachers $\left(\mathrm{PT}_{7}, \mathrm{PT}_{11}, \mathrm{PT}_{14}, \mathrm{PT}_{17}, \mathrm{PT}_{19}, \mathrm{PT}_{21}\right.$ ) suggested the use of a mirror whereas a total of 3 prospective teachers (PT7, PT11, PT21) recommended the use of a clock. In this sense, it is notable that a total of 3 prospective teachers considered appropriate to use both of the two materials. Among the suggestions for the sixth question, there was the practice of paper folding, which has been suggested for all questions except for the fifth question ( $\left.\mathrm{PT}_{8}, \mathrm{PT}_{18}, \mathrm{PT}_{20}\right)$. One of the prospective teachers favored visual expression ( $\left.\mathrm{PT}_{13}\right)$; one of them suggested computer software $\left(\mathrm{PT}_{20}\right)$, and one featured the use of question and answer method $\left(\mathrm{PT}_{25}\right)$, and there was one prospective teacher $\left(\mathrm{PT}_{1}\right)$ who argued that explaining it in detail on the board would help the student correct the mistake. Yet, one of the prospective teachers $\left(\mathrm{PT}_{5}\right)$ avoided answering the question while the suggestions provided by 2 prospective teachers $\left(\mathrm{PT}_{10}, \mathrm{PT}_{16}\right.$ ) failed to focus on correcting the mistake.

\section{Results, discussion and suggestions}

This study examined the explanations of the senior prospective middle school mathematics teachers in regard to the mistakes related to reflection symmetry, which were assumed to be made by students.

The findings of the study indicated that the prospective teachers generally failed to do anything else other than simply describing the mistake (e.g. the student completed the triangle, wrote the word in reverse, displaced the shape, etc.) in identifying the right and wrong steps in the potential answers of six students. They did not provide any explanation for the source of such mistakes. Yet, it is important to know the types of misconceptions and to realize the development of such misconceptions in order to eliminate any existing misconception in students (Yenilmez \& Yaşa, 2008). Also, Ball (1991) emphasized the importance of considering conceptual errors from the perspective of students and understanding the conceptual thinking underlying such errors for teachers. In this regard, it is essential to reveal whether teachers have internalized the concept that they will teach or not. Teaching, otherwise, may lead to major problems.

It is also notable, based on the findings on the identification of the right and wrong steps by the prospective teachers, that some of the prospective teachers themselves were mistaken while identifying the wrong steps. These prospective teachers provided certain explanations, including that the axis of symmetry should be parallel either to the horizontal axis or to the vertical axis and that it is impossible to form a symmetrical shape for certain shapes.The intersection of the symmetry line with the shape (object) is an important variable and it is a known thatthis influences how students draw the symmetry of object (shape) with respect to the line (Köse, 2012). On the other hand, it seems that some participants have confused symmetry of an object with objects being symmetrical, especially in the second question. These candidates examined whether the two different shapes involved in the question were symmetrical or not, by takingshapes as a whole. However, the context of the problem is about whether the symmetry of the given shape is taken correctly or not. This may be cause of the prospective teachers are not able to read or understand the question carefully, or it may be related to the education they have received. Because, in education given to schools, geometric shapes are generally studied and they are asked to draw symmetry axes of these shapes. Thus, such an understanding may have led the participants to think shapes as a whole. The study by Turgut, Yenilmez \& Anapa (2014) concluded that the prospective teachers had difficulty in finding the axis of symmetry and determining whether the given two objects are symmetrical or not. It may be argued that the prospective teachers in this study experienced some similar difficulties and fell into misconception. Further, there were some prospective teachers who avoided answering the questions addressed to them and reported that they did not understand what the assumed student did. All of these findings demonstrated that the prospective teachers do not have sufficient knowledge on reflection symmetry. These findings are similar to the findings in the study by Gürbüz \& Durmuş (2009), Desmond (1997) and Son (2006). The prospective teachers who participated in the study of Son (2006) also pointed out procedural ways to correct mistakes, although they made conceptual insights while describing them.

The results of the study reveal that the prospective teachers evaluated the mistakes of the assumed student by focusing on the operation, rather than from a conceptual perspective. This is similar to the findings of the studies by Son \& Sinclair (2010), Baki \& Kartal (2004). Another important finding of the study indicated that the participants did not use mathematical terminology and jargon in identifying the mistakes of the student. However, one of the general purposes of mathematics 
education in the curriculum is that: "the student is required to use mathematical terminology and jargon in an accurate way in order to rationalize, reason and share his or her mathematical thinking" (MEB, 2013). Accordingly, it is an issue of concern how the prospective teachers who do not sufficiently use mathematical terminology and jargon could achieve such purpose in service. The studies by Köse (2012) and Bintaş, Altun \& Arslan (2003) revealed similar findings.

The most common suggestions of the participants for the potential mistakes were " I would make the student repeat the rules of symmetry", but in this expression, candidates do not clearly state what they mean and what they will do. On the other hand, other candidates have discourses such as "I would make the student practice more often" and "I would give examples of daily life", but they have not given me any clues as to what kind of exercises or examples of daily life can be used. Therefore, participants did not provide concrete examples. Thus, it can be stated that the lack of any explanation where the prospective teachers attempted to comprehend the reason for the misconceptions indicated that they failed to have a deep understanding of the concept. On the contrary, teachers are required to have a very good knowledge of mathematics in order that their teaching can be qualified (Gürbüz \& Durmuş, 2009; Zembat, 2007). Also, notably, the prospective teachers stated that they mentioned some procedural processes such as using a mirror or paper folding in forming a symmetrical shape in almost all questions where they were asked to suggest a solution for the mistake of the students. In a similar way, the prospective teachers in the study by Son (2006) offered some conceptual insights to describe the student mistakes, but they focused on procedural processes to provide a solution for the mistakes.

In conclusion, this study puts forth that the prospective teachers failed to develop a sufficient strategy to overcome the student mistakes. The studies by AydınGüç, \& Hacısalihoğlu-Karadeniz (2016), Berg \& Brouwer (1991), Smith \& Neale (1989) and Son (2006) concluded similar results. The Updated Secondary School Mathematics Teaching Program (MEB, 2013) anticipates that students make use of concrete experiences, intuitions, informal information that they have in their daily life in order to support conceptual learning. Considering that, teachers are expected to prepare environments where students are able to relate their existing knowledge to the new knowledge that they have access to (Hacısalihoğlu-Karadeniz et al. 2015). Conceptual knowledge consists of the meanings underlying rules, generalizations, their relationships and operations (Bekdemir, Okur \& Gelen, 2010). In order for the concept of a subject to be fully acquired by a student, the definitions and properties of such concept are required to be completely and accurately explained (Küçük \& Demir, 2009). Otherwise, it is reported that students tend to memorize the operations based on the concept and definitions; for that reason, more emphasis should be placed on conceptual learning in this process so as to overcome such difficulty (Hacısalihoğlu-Karadeniz et al. 2015). In conclusion, the acquisition of something is indispensable in conceptual knowledge; on the other hand, procedural knowledge features how to use a concept or an operation and may overlook the reason underlying such concept or operation (Baki, 1997).

The results of the study showed that the prospective teachers could not provide conceptual explanations in identifying the student mistakes and suggesting a solution. Therefore, it may be recommended that the relevant field and training courses in teacher training programs should focus more on mathematical concepts. If lecturers present some potential student mistakes on mathematical concepts, the prospective teachers may be encouraged to discuss these mistakes and provide a solution. The prospective teachers are required to learn how to relate conceptual and procedural knowledge in pre-service period. Understanding of an issue is the focal point of conceptual understanding. However, there is no need to know the reason of the reason of a concept or procedure it is enough to know how to use it t (Baki, 1997). In this sense, it is important in this process that the prospective teachers step out of traditional-familiarknown methods and adopt a student-oriented approach. Also, the prospective teachers should be given the opportunity to put into practice various methods and comprehensive techniques, which are discussed during their education, in their field courses. In the updated teaching programs and course books, more focus might be placed on teaching concepts and more exercises may be included from primary education to secondary education level. For instance, although the activities such as paper folding involve a procedural process, they can be sometimes effective in teaching mathematical concepts or recalling the concepts previously learnt (HacısalihoğluKaradeniz, 2017). However, it should be attended to the fact that applications made by the paper folding method reveal the mathematical gains, so that the initial aim is to teach mathematics. Otherwise, activities and practices with paper folding can only be limited to having fun (Hacısalihoğlu-Karadeniz, 2017)

The data collection tool in this study was an open-ended test. However, a further study might interview the prospective teachers in order to obtain more in-depth data, along with such test. In this way, it would be clear why the prospective teachers provided some explanations in identifying the mistakes and suggesting a solution to these mistakes. Such researches can also be carried out for different mathematical concepts which are thought to be difficult for teacher candidates.

\section{References}

Aksoy, Y., \& Bayazit, i. (2010). Examination of the difficulties encountered in learning and teaching the concepts of symmetry in an analytical approach. In E. Bingölbali, M.F. Özmantar, Mathematical difficulties and solution proposals encountered in primary (pp. 187. 215). Ankara: Pegem Academy.

Aydın Güç, F., \& Hacısalihoğlu Karadeniz, M. (2016). Examining the Mental Addition Strategies That Are Used by The Secondary School Students. Journal of Kirsehir Education Faculty, 17(3). 
Baki, A., (1997). Educating mathematics teachers, Medical Journal of Islamic Academy of Sciences, 10(3)

Baki, A., \& Kartal, T. (2004). Characterization of high school students'algebra information in the context of conceptional and operational knowledge.Türk Eğitim Bilimleri Dergisi, 2(1), 27-50. Doi: http://www.tebd.gazi.edu.tr/index.php/tebd/article/vie w/198

Baki, A. (2006). Kuramdan uygulamaya matematik eğitimi[Mathematics education from theory to practice]. Trabzon: Derya Kitabevi.

Ball, D. L. (1991). Implementing the Professional Standards for Teaching Mathematics: What's All This Talk about Discourse?. Arithmetic Teacher, 39(3), 44-48.

Bekdemir, M., Okur, M., \& Gelen, S. (2010). The effects of 2005 elementary mathematıcs education curriculum on the elementary seventh grade students' conceptual and procedural knowledge and skills. Journal of Erzincan University Education Faculty, 12(2).

Berg, T., \& Brouwer, W. (1991). Teacher Awareness of Student Alternate Conceptions about Rotational Motion and Gravity. Journal of Research in science teaching, 28(1), 3-18.

Bintaş, J., Altun, M., \& Arslan, K. (2003). Teaching symmetry with realistic mathematics education. MATDER, retrieved from http://www.matder.org.tr/index.php?option=com_con tent\&view $=$ article\&id=57:simetriogretimi\&catid=8: matematik-kosesimakaleleri\&Itemid $=172$

Birgin, O., \& Gürbüz, R. (2009). Investigation of primary school students' operational and conceptual knowledge level about the rational numbers. Journal of Uludağ University Education Faculty, 22(2), 529-550. doi:

http://www.acarindex.com/dosyalar/makale/acarinde $\mathrm{x}-1423935447 . p d f$

Case, M.J., \& Fraser, D.M. (1999). An Investigation Into Chemical Engineering Students' Understanding of The Mole and The Use of Concrete Activities to Promote Conceptual Change, International Journal of Science Education, 21(12), 1237-1249.

Desmond, N. S. (1997). The geometric Content Knowledge of Prospective Elementary Teachers, Dissertation.1997. 233 f. Dissertation (Doctor of Philosophy) - The Faculty of the Graduate School of University of Minnesota, Minneapolis.

Gürbüz, K., \& Durmuş, S. (2009). The qualification levels of in-service elementary school teachers on the sublearning strands, namely transformational geometry, geometric objects, pattern and tessellations. Journal of Abant İzet Baysal University Education Faculty, 9(1). doi: http://dergipark.ulakbim.gov.tr/aibuefd/article/viewFil e/5000091410/5000084782

Hacısalihoğlu Karadeniz, M., Baran, T., Bozkuş, F., \& Gündüz, N. (2015). Difficulties of Prospective Elementary Mathematics Teachers' Regarding to
Reflection Symmetry. Turkish Journal of Computer and Mathematics Education (TURCOMAT), 6(1), 117-138.

Hacısalihoğlu Karadeniz, M. (2017). Mathematics Teaching via Paper Folding Method. Elementary Education Online, 16(2), 663-692.

Hoyles, C., \& Healy, L. (1997). Unfolding Meanings For Reflective Symmetry. International Journal of Computers for Mathematical Learning, 2(1), 27-59.

Kaplan, A., \& Öztürk, M. (2014). Analysis of 2nd-8th Grade Students' Thinking Approaches Toward Understand the Concept of Symmetry. Elementary Education Online, 13(4), 1502-1515.doi: http://dergipark.ulakbim.gov.tr/ilkonline/article/viewFi le/5000075294/5000070250

Karadağ, E. (2010). Research Models Used in Doctoral Dissertations in the Area of Education Sciences in Turkey: Quality of Research and Analytical Errors. Educational Administration: Theory and Practice, 16(1), 49-71

.Köse, N. Y., \& Özdaş, A. (2009). How Do The Fifth Grade Primary School Students Determine The Line of Symmetry in Various Geometrical Shapes Using Cabri Geometry Software?. Elementary Education Online, 8(1), 159-175. Retrieved from http://ilkogretimonline.org.tr/vol8say1/v8s1 m13.pdf?origin=publicatio n_detail

Köse, N. Y. (2012). Primary School Students' Knowledge of Line Symmetry. Hacettepe Universıtesı Egıtım Fakultesı DergISI, 42, 274-286.

Küchemann D. (1981). Reflection and Rotation. In K. Hart, Children's understanding of mathematics (pp. 137-157). London: John Murray

Küçük, A., \& Demir, B. (2009). A Study on Some Misperceived Concepts in the Teaching of Mathematics in 6th-8th Grades. Dicle University Journal of Ziya Gokalp Education Faculty, 13.

Leikin, R., Berman, A., \& Zaslavsky, O. (1998). Definition of Symmetry. Symmetry: Culture and Science: Order and Disorder, 9(2-4), 375-382.

Leikin, R., Berman, A., \& Zaslavsky, O. (2000). Applications of Symmetry to Problem solving. International Journal of Mathematical Education in Science and Technology, 31(6), 799-809.

MEB. (2013). Middle School Mathematics Education Program. Retrieved from http://ttkb.meb.gov.tr/program2.aspx?islem=1\&kno=2 15

Oliver, A. (1989). Handling Pupils' Misconceptions. Presidential Address Delivered at the Thirteenth National Convention on Mathematics,.Physical Science and Biology Education, Pretoria,; 1 ; 3-7 July 1989.

[http://academic.sun.ac.za/mathed/Malati/Misconcept ions.htm]. 
Orb, A., Eisenhauer, L., \& Wynaden, D. (2001). Ethics in qualitative research. Journal of nursing scholarship, 33(1), 93-96.

Orton, J. (1999). Children's perception of pattern in relation to shape. In A. Orton, Pattern in the teaching and learning of maths. London: Cassell, 149-167.

Seidel, J. (1998). Symmetry in season. Teaching Children Mathematics, 4, 244-246.

Smith, D. C., \& Neale, D. C. (1989). The construction of subject matter knowledge in primary science teaching. Teaching and teacher Education, 5(1), 1-20. Retrieved from http://www.sciencedirect.com/science/article/pii/0742 $051 \times 89900152$

Smith, J.P., diSessa, A.A., \& Roschelle, J. (1993). Misconceptions reconceived: A constructivist analysis of knowledge in transition. The Journal of the Learning Sciences, 3(2): 115-163. Retrieved from http://www.jstor.org/stable/1466679?seq=1\#page_sca n_tab_contents.

Son, J. W. (2006). Investigating preservice teachers'understanding and strategies on a student's errors of reflective symmetry. Proceedings of the 30th of the International Group for the Psychology of Mathematics Education, 5, 146-155. Retrieved from http://files.eric.ed.gov/fulltext/ED496939.pdf\#page $=15$
Son, J. W., \& Sinclair, N. (2010). How preservice teachers interpret and respond to student geometric errors. School Science and Mathematics, 110(1), 31-46.

Swan, M. (2001). Dealing with misconceptions in mathematics. In P. Gates, Issues in mathematics teaching (pp. 147-65). London: Routledge Falmer

Turgut, M., Yenilmez, K., \& Anapa, P. (2014). Symmetry and rotation skills of prospective elementary mathematics teachers. Bolema: Boletim de Educação Matemática, 28(48), 383-402.

Yenilmez, K., \& Yaşa, E. (2008). Misconceptions of elementary school students in geometry. Journal of Uludağ University Education Faculty, 21(2), 461-483.

Zaslavsky, O. (1994). Tracing students' misconceptions back to their teacher: A case of symmetry. Pythagoras, $33,10-17$

Zembat, i. Ö. (2007). The main tenets of direct Instruction and constructivism: the case of translations. Journal of Gazi Education Faculty, 27(1). doi: http://dergipark.ulakbim.gov.tr/gefad/article/view/500 0078650/5000072871

Zembat, I. O. (2010). Prospective elementary teachers' conceptions of volume. Procedia-Social and Behavioral Sciences, 2(2), 2111-2115.

Weyl, H. (1952). Symmetry. Princeton: Princeton University Press. 